\title{
Decisão diante de conflitos bioéticos e formação em odontologia
}

Michelli Justen ${ }^{1}$, Fabiana Schneider Pires ${ }^{1}$, Cristine Maria Warmling ${ }^{1}$

1. Universidade Federal do Rio Grande do Sul, Porto Alegre/RS, Brasil.

\section{Resumo}

O objetivo deste estudo é relacionar concepções sobre ética com a capacidade de tomada de decisão de estudantes no estágio inicial do curso de odontologia. Trata-se de pesquisa qualitativa, dividida em duas etapas: na primeira, 62 participantes responderam a um formulário on-line com duas perguntas sobre concepções de ética; na segunda, 59 deliberaram sobre duas situações de saúde envolvendo conflitos bioéticos. As respostas passaram por análise textual discursiva, por meio da qual se verificou que a maioria dos estudantes compreende a ética como orientação individual nas condutas sociais e profissionais. Essa concepção restrita de ética aparece também nos exercícios de tomada de decisão. Conclui-se que o ensino de bioética deve contemplar o papel de contextos singulares na tomada de decisão, enfatizando o respeito à vida, e não apenas o tratamento de doenças. Tal ensino, inserido de maneira transversal na formação, valoriza o cuidado centrado nas pessoas.

Palavras-chave: Análise ética. Educação superior. Ética odontológica. Tomada de decisão clínica.

\section{Resumen}

\section{Decisión frente a conflictos bioéticos y formación en odontología}

El objetivo de este estudio es relacionar concepciones sobre ética con la capacidad de toma de decisiones de estudiantes en la etapa inicial del curso de odontología. Se trata de una investigación cualitativa, dividida en dos etapas: en la primera, 62 participantes respondieron a un formulario en línea con dos preguntas sobre concepciones de ética; en la segunda, 59 participantes deliberaron sobre dos situaciones de salud que implican conflictos bioéticos. Las respuestas se sometieron a un análisis textual discursivo, por medio del cual se constató que la mayoría de los estudiantes comprende la ética como una orientación individual en las conductas sociales y profesionales. Esta concepción restringida de la ética aparece también en los ejercicios de toma de decisiones. Se concluye que la enseñanza de la bioética debe contemplar el papel de los contextos singulares en la toma de decisiones, haciendo hincapié en el respeto por la vida, y no solo en el tratamiento de enfermedades. Tal enseñanza, inserida de manera transversal en la formación, valoriza el cuidado centrado en las personas.

Palabras clave: Análisis ético. Educación superior. Ética odontológica. Toma de decisiones clínicas.

\begin{abstract}
Decision-making in the face of bioethical conflict and training in Dentistry

This study aims to understand the relationship between conceptions of ethics and decision making in situations of bioethical conflict in practices of first-year dentistry students. Holistic case study with a qualitative approach was carried out, in two steps: in the first, 62 participants answered an online form with two questions about conceptions of ethics; in the second, 59 deliberated on two health situations with bioethical conflict. Discursive textual analysis was performed. Results show that students understand ethics as individual guidance in social and profession conduct. In training, students' restricted conceptions of ethics are amplified in the decision-making exercises in the face of bioethical conflicts. The role of singular contexts is an element for the decision-making in learning that includes respect for life and not just the treatment of disease. The topic of bioethics, thus transversalized in the formative process, values people-centered care.
\end{abstract}

Keywords: Ethical analysis. Education, higher. Ethics, dental. Clinical decision-making. 
A bioética analisa como a vida das pessoas pode ser afetada pelo desenvolvimento científico e tecnológico na área da saúde. Sua aplicação compreende deliberações individuais ou coletivas sobre o uso de tecnologias que envolvem a vida, encontrando-se ligada ao próprio sentido de humanidade ${ }^{1}$. A análise de casos singulares, associada a modelos filosóficos, apoia a reflexão bioética. Esse paradigma casuístico de análise parte das circunstâncias particulares de um caso para detectar o cerne ético da situação. Na tomada de decisão, para enfrentar conflitos, emergem princípios bioéticos primários, como autonomia, beneficência, não maleficência, justiça e outros derivados (fidelidade, veracidade e confidencialidade) ${ }^{1,2}$.

Análises críticas dos códigos deontológicos, responsáveis por orientar a conduta profissional em procedimentos terapêuticos, vêm demonstrando que esses documentos privilegiam a proteção do profissional, evidenciando posturas corporativistas sustentadas em prescrições para resolver conflitos éticos ${ }^{3,4}$. A qualidade do cuidado, porém, está relacionada à competência bioética do profissional. O juízo próprio ou a intuição, por si sós, não podem fundamentar as escolhas; eles devem estar associados a embasamento e estudos éticos. A capacidade de decidir pressupõe responsabilidade moral pelas escolhas. O caráter dinâmico dos acontecimentos depõe contra fórmulas ou regras de ação. O juízo ético dependerá da análise da realidade em questão ${ }^{2,5,6}$.

A formação em saúde transcende métricas de diagnóstico, terapêutica, tratamento, prognóstico, etiologia e profilaxia de doenças e agravos, pois abrange competências e habilidades que permitem ao profissional compreender as necessidades das pessoas em seus contextos sociais. Assim, construir e pactuar projetos terapêuticos que incentivem a corresponsabilização pressupõe a humanização do cuidado $^{7}$ - compreendendo "humano", aqui, não como uma conquista da razão, mas como valor que reside nas relações do sujeito com a própria história, cultura e sociedade ${ }^{8}$.

Considerando a formação em saúde, uma pergunta guia o presente estudo: quando expostos a situações profissionais que exigem a tomada de decisão, como estudantes manejam conceitos éticos que trazem consigo de suas realidades sociais e familiares? Participaram da pesquisa alunos do estágio inicial da graduação em odontologia. Partindo de suas falas, o estudo pretende compreender e propor processos de ensino da bioética na formação profissional em saúde.

\section{Método}

$\mathrm{O}$ artigo traz resultados de estudo de caso com abordagem qualitativa, de tipo holístico, isto é, concentrado em analisar o fenômeno em sua globalidade, e não as particularidades dos $\operatorname{casos}^{9}$. A amostra foi composta por estudantes de uma universidade federal no Sul do Brasil que frequentavam a disciplina de bioética ministrada no primeiro semestre do curso de odontologia. A coleta de dados ocorreu em 2018 e abrangeu duas turmas, uma do turno diurno (40 estudantes) e outra do noturno (23 estudantes). Os 63 estudantes todos cursavam a disciplina de bioética - foram convidados a participar.

A coleta de dados foi dividida em dois momentos. Do primeiro, em agosto de 2018, participaram 62 estudantes, que responderam a um formulário on-line com duas perguntas abertas: "O que é ética para você?" e "Como você vê a importância da ética na profissão de odontologia?". Do segundo momento, em setembro de 2018, participaram 59 estudantes ( 36 do diurno e 23 do noturno). Foram apresentadas duas situações, propostas e analisadas em Zoboli ${ }^{6}$ (Quadro 1). Os participantes foram convidados a se colocar no papel de um profissional da saúde e descrever a conduta que adotariam ante essas situações. O objetivo foi compreender como os princípios primários da bioética (autonomia, beneficência, não maleficência e justiça) seriam usados pelos estudantes na tomada de decisão diante de conflitos bioéticos.

As respostas dos estudantes foram examinadas por meio da análise textual discursiva, dividida nos seguintes procedimentos: pré-análise, estudo exploratório e interpretação de informações produzidas para codificação e estruturação dos discursos em unidades de análise ${ }^{10}$. Os participantes assinaram termo de consentimento livre e esclarecido. A fim de garantir a confidencialidade dos estudantes, as falas foram codificadas com a letra "E" seguida de um número. 
Quadro 1. Possíveis situações de conflito bioético de acordo com as matrizes de intervenção de Zoboli ${ }^{6}$

Preservando a confidencialidade

(36 estudantes, do período diurno, responderam)

Atendendo adolescentes

(23 estudantes, do período noturno, responderam)
$O$ senhor $M$ tem sífilis. Ele não quer contar o que tem para a esposa, mas quer protegê-la da doença. Enquanto está em tratamento, $M$ pede que o exame de sífilis seja feito em sua esposa sem que ela saiba.

B, 15 anos de idade, procura a unidade básica de saúde e conta que recentemente se apaixonou por um rapaz de 16 anos. Seus pais acham que ela é muito jovem e a proíbem de namorar. A jovem diz que ainda não tem vida sexual ativa, mas pede uma prescrição de anticoncepcional oral. Ela também pede que nada seja contado aos seus pais.

\section{Resultados e discussão}

\section{Da bioética individual à bioética social}

O objetivo da bioética pode ser caracterizado como o desenvolvimento da empatia e da solidariedade nas pessoas que exercem o cuidado em saúde. Ao propor diálogos com ciências e tecnologias da saúde, a bioética humaniza a assistência e abre possibilidades para que os profissionais compreendam as razões de suas próprias decisões ${ }^{11,12}$. No entanto, a análise do discurso dos alunos do estágio inicial da graduação em odontologia evidencia dificuldades em discernir o conceito de bioética do conceito de moral. Muitas vezes, a definição é abstrata, como percebido também em outro estudo, de Lima e Souza ${ }^{13}$.

"[A bioética] é um conjunto de regras e conceitos que visam valorizar a moral e a individualidade de cada indivíduo" (E54).

"É um conjunto de 'regras" que não estão impostas na Constituição, porém a maioria dos seres humanos as pratica. Sabemos que não é permitido ir trabalhar de chinelos, por exemplo, pois esta ação é considerada antiética, inapropriada para tal local" (E28).

"São os princípios que orientam, disciplinam/educam, motivam o comportamento humano. É o consentimento entre o que é certo e o que é errado para cada caso/ocorrido/ser humano" (E58).

Os estudantes compreendem a ética como norteadora de ações, tanto para benefício do indivíduo quanto da sociedade. Os discursos valorizam uma concepção de ética centrada na orientação individual para comportamentos sociais. Em certa medida, os alunos já trazem consigo - provavelmente antes mesmo de a disciplina de bioética ser ministrada a consciência da importância da ética como ferramenta que orienta a tomada de decisões.

"Acredito que a ética seja um conjunto de princípios que deveriam estar presentes em cada cidadão, em busca de uma sociedade mais justa e digna. A partir do pensamento ético dos indivíduos, alguns valores como respeito e responsabilidade perpetuam-se no ambiente, colaborando para um espaço mais acessível e agradável a todos que nele convivem. A ética também é importante no momento de tomar decisões corretas e muitas vezes é utilizada como uma ferramenta para julgar o certo e o errado, resultando em justiça. Mas, sobretudo, acredito que a ética seja essencial para tornar uma sociedade devidamente desenvolvida nas relações humanas" (E5).

"Ética são os meus princípios, o meu comportamento com o próximo, a minha conduta com qualquer pessoa e, nesse caso, com os meus futuros pacientes. Ética não são leis. Por mais que tenham princípios éticos para determinadas profissões, tem pessoas que seguem, outras não. É algo muito mais pessoal e que deve ser construído para o bem da sociedade" (E16).

"Ética é o conjunto de princípios baseados nos valores culturais e históricos de uma sociedade, que visa conduzir nossa conduta dentro da sociedade como participantes dela, tanto em nossas ações coletivas como nas individuais" (E31).

As falas valorizam a importância da ética na formação profissional, mas permanecem na esfera 
teórica, descoladas de possibilidades de aplicação dos conceitos em situações práticas do trabalho em saúde. Essas concepções mais abstratas podem ser insuficientes ante a complexidade e as exigências do cotidiano. Por isso os percursos formativos de bioética, independentemente da área profissional, têm o desafio de problematizar tais conceitos, aproximando-se das práticas profissionais e pensando grandes temas e dinâmicas da atualidade.

A abordagem de temas bioéticos em cursos de saúde pode ser vivida como uma experiência hipercrítica, mas abstrata, ou pode ampliar a ação política, em um constante escrutínio daquilo que se diz, se pensa e se faz ${ }^{14}$. Nessa última opção, é possível tratar de questões que vão além do "portar-se bem profissionalmente", chegando à reflexão sobre a experiência ética na tomada de decisão ${ }^{15}$.

\section{Bioética na formação e na prática profissional}

Modelos e práticas de saúde tradicionalmente voltados à visão biomédica objetificam as práticas ${ }^{13}$. No entanto, embora a técnica seja central na odontologia, a assistência não deveria se pautar unicamente na excelência da técnica, mas também no reconhecimento e compreensão das necessidades do paciente. Como cuidado em saúde, a prática odontológica se estabelece em relações de intersubjetividade. As abordagens centradas apenas em aspectos técnicos são insuficientes para promover a responsabilidade do profissional com a qualidade de vida das pessoas ${ }^{16}$. Nesse sentido, a bioética desperta a atenção dos profissionais para dilemas que o paciente enfrenta em seu cotidiano.

Valores éticos são parte constitutiva da ação, uma vez que a orientam, e por isso as práticas em saúde se relacionam com a bioética ${ }^{17}$. Nessa perspectiva, contraposta à deontologia (constituída como ramo que compreende a ética como dever moral), os valores antecipam-se à ação. A deontologia enfatiza o "fazer o que é correto", o cumprimento de um código e o "bom comportamento" profissional, limitando os conflitos éticos a problemas de ordem interpessoal, técnica ou, ainda, jurídica ${ }^{18}$.

O discurso dos participantes salienta a relação entre formação individual e conduta profissional, numa tendência observada também na pesquisa de Lima e Souza ${ }^{13}$. Para os estudantes, o profissional ético deve ter senso de justiça e compromisso com colegas e pacientes.

"Enxergo a ética na profissão de odontologia como fator crucial para o desempenho desta profissão, pois a conduta ética é basal para profissionais que lidam diariamente com pessoas. A saúde é direito inerente de qualquer cidadão. Caso um cirurgião-dentista apresente qualquer conduta que fira a ética, discriminando algum indivíduo seja por classe social, raça ou opção sexual, ele está impedindo o direito mais básico do ser humano, a assistência à saúde" (E6).

"Em todas as profissões é imprescindível que o profissional seja extremamente responsável. Com a odontologia não é diferente. Um cirurgião-dentista deve sempre colocar à frente de tudo os seus princípios e ter em mente que está lidando com outros seres humanos. A ética o transforma em um profissional competente e sensato, sempre respeitando seja o seu paciente seja o seu colega de trabalho, sendo assim não somente um dentista de qualidade, mas também um ser humano melhor" (E7).

"É importante que um profissional formado em odontologia cumpra com ética para que seja um bom profissional, tanto com seus pacientes quanto com seus colegas de trabalho. Ética profissional envolve solidariedade e comprometimento com o outro, além de respeito, que é muito importante em qualquer profissão" (E11).

"Para mim, a ética é uma das coisas mais importantes em qualquer profissão, mas principalmente para a área da saúde, na qual estamos lidando com pessoas, vidas e sentimentos. Muito mais importante do que a habilidade manual, a ética está relacionada ao cuidado do meu paciente, não só o cuidado mecânico, mas humanizando o paciente, do jeito que deve ser. Não tratando ele roboticamente, mas sim enxergando todos os ângulos, os medos e anseios que qualquer ser humano carrega consigo. (...) O paciente não é apenas um cliente, mas sim e acima de tudo - uma pessoa, a qual merece ser tratada com respeito e dignidade. Ademais, considerando o país repleto de desigualdade em que vivemos, os valores éticos se mostram essenciais a fim de que o atendimento odontológico 
seja completo e acessível a todas as realidades, promovendo qualidade de vida e bem-estar às diferentes camadas da população" (E27).

"Para que na profissão possamos ter uma boa relação com colegas e pacientes, é necessário que haja a ética - um conjunto de ações relacionadas aos valores pessoais e impostos pela sociedade a um indivíduo - no que diz respeito a (...) tratar alguém. Como exemplo temos o sigilo profissional" (E30).

Não se espera que estudantes recém-ingressados no curso de odontologia tenham fundamentos suficientes para resolver conflitos bioéticos ${ }^{17}$. Porém o cenário poderia ser melhor se mais do que apenas $31,3 \%$ dos cursos de odontologia do Brasil tivessem a bioética como disciplina obrigatória, segundo dados de 2007 e de $2008^{11}$. Além disso, ainda são escassas as pesquisas brasileiras referentes à bioética na odontologia ${ }^{19}$.

Uma postura ético-política de engajamento pode ser estimulada por um ambiente de formação que continuamente questiona atitudes ${ }^{20-22}$. Quando aprende sobre determinantes sociais da saúde, o estudante torna-se capaz de olhar para situações de adoecimento para além da perspectiva clínica, desenvolvendo empatia pelo paciente que enfrenta uma série de dificuldades para acessar o sistema de saúde. A bioética expõe aquilo que se enxerga, mas não se vê.

Nos cursos de odontologia, a bioética desenvolve valores relacionados ao cuidado da pessoa ${ }^{23,24}$, possibilitando que os estudantes entrem em contato com experiências de conflito ético e ampliem conhecimentos práticos e teóricos que serão importantes em sua trajetória profissional. Temas bioéticos podem ser trabalhados em todos os momentos da grade curricular, de modo transversal. Esses temas devem acompanhar o envolvimento dos estudantes com a prática clínica, fazendo crescer, quase naturalmente, a sensibilidade do aluno a aspectos subjetivos e sociais da relação com o paciente.

\section{Deliberação e tomada de decisão: valores em conflitos bioéticos}

Segundo Zoboli ${ }^{6}$, para a situação "Preservando a confidencialidade" (Quadro 1), os possíveis cursos de ação se situam entre dois extremos: ou se sacrifica a veracidade na relação clínica, mentindo para a esposa, ou se respeita a confidencialidade e privacidade do marido. O Quadro 2 apresenta a categorização das respostas dos participantes do presente estudo, comparando-as com os cursos de ação encontrados no trabalho de Zoboli ${ }^{6}$.

Quadro 2. Respostas dos estudantes de odontologia à situação "Preservando a confidencialidade", classificadas segundo cursos de ação propostos por Zoboli ${ }^{6}$

\begin{tabular}{|c|c|c|}
\hline Classificação Zoboli ${ }^{6}$ & Cursos de ação & Respostas ( $n=36)$ \\
\hline A & $\begin{array}{l}\text { Solicitar exame de diagnóstico de sífilis para a esposa somente depois } \\
\text { que o marido lhe contar a verdade }\end{array}$ & 18 \\
\hline G & O profissional deve contar para a esposa & 7 \\
\hline $\mathbf{X}^{*}$ & Encaminhar o caso para outro profissional & 4 \\
\hline J & Profissional deve se negar a fazer o exame sem consentimento & 2 \\
\hline D & Solicitar exames a esposa sem que ela saiba & 2 \\
\hline K & $\begin{array}{l}\text { Advertir a esposa sobre a doença e solicitar exame, sem contar a verdade } \\
\text { sobre o marido }\end{array}$ & 2 \\
\hline $\mathbf{F}$ & $\begin{array}{l}\text { Chamar a esposa na Unidade Básica de Saúde para o marido e o } \\
\text { profissional da saúde contarem sobre a sífilis e, se ela aceitar, } \\
\text { solicitar o exame }\end{array}$ & 1 \\
\hline
\end{tabular}

${ }^{*} O$ curso de ação X não aparece no estudo de Zoboli, mas foi identificado no presente estudo. 
Figura 1. Delineamento esquemático explicativo do Quadro 2

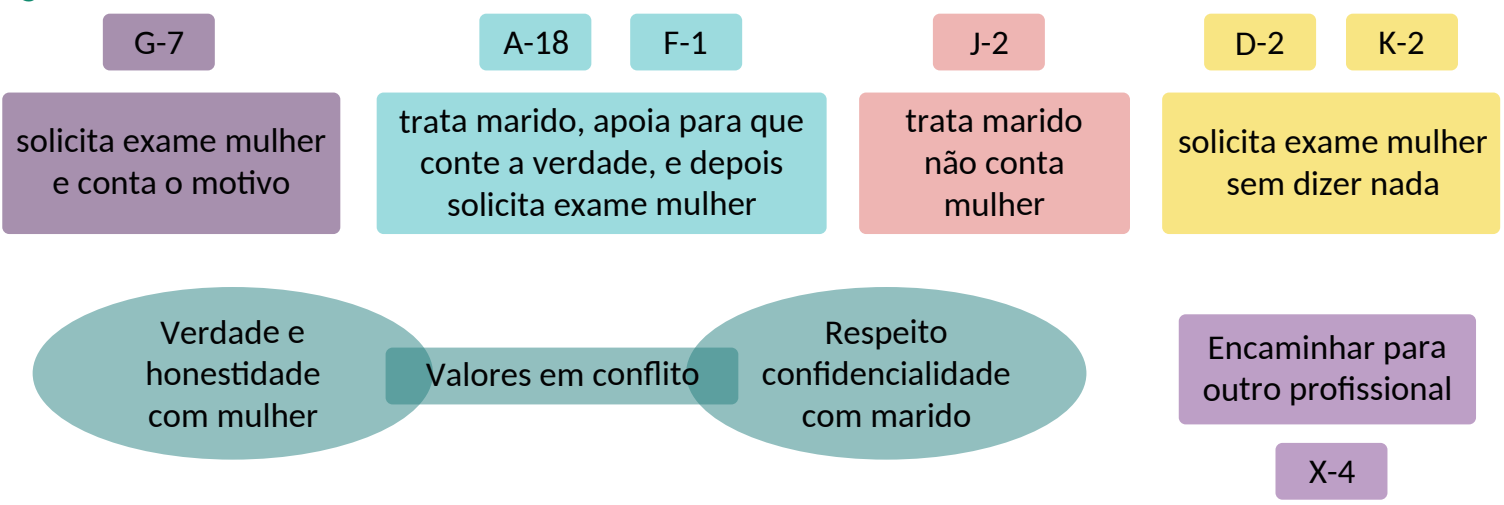

Diante do conflito bioético, verifica-se que o valor intrínseco privilegiado pelos estudantes foi a proteção da vida. A situação levou a maioria dos estudantes a optar por cursos de ação intermediários, resultado que vai ao encontro da pesquisa de Zoboli ${ }^{6}$. Destaca-se que houve maior diversidade de cursos de ação no estudo de referência (13) em comparação com o presente estudo (7). É preciso ressaltar também a diferença na caracterização das amostras: no estudo de Zoboli ${ }^{6}$, os participantes eram médicos e enfermeiros já inseridos na prática profissional e, portanto, provavelmente com vínculos mais fortes com pacientes.

Na presente investigação, houve mais adeptos ao valor extremo de honestidade e valorização da mulher (Figura 1). A composição da amostra, com maior número de mulheres
$(72,6 \%)$, pode explicar esse resultado, que indica um aspecto de representatividade de gênero na deliberação bioética.

Verifica-se também que nenhum enfermeiro do estudo de Zoboli ${ }^{6}$ optou pelo curso de ação "encaminhar para outro profissional", enquanto quatro estudantes de odontologia escolheram essa alternativa. Esse resultado pode estar relacionado a vínculos e experiências pessoais nos serviços de saúde, ainda distantes dos estudantes em início de curso.

Com relação à situação "Atendendo adolescentes", os dois extremos em conflito são o respeito à confidencialidade da adolescente e o respeito à responsabilidade dos pais ${ }^{6}$. Nesta situação, verifica-se que a maioria dos estudantes optou por orientar a adolescente quanto ao uso de métodos contraceptivos (Quadro 3).

Quadro 3. Respostas dos estudantes de odontologia à situação "Atendendo adolescentes", classificadas segundo cursos de ação propostos por Zoboli ${ }^{6}$

\begin{tabular}{clc} 
Classificação Zoboli & \multicolumn{1}{c}{ Cursos de ação } & Respostas (n=23) \\
D & O profissional deve indicar o preservativo e conversar com os pais & 7 \\
B & $\begin{array}{l}\text { Explicar sobre métodos contraceptivos e orientar que a paciente converse } \\
\text { com os pais }\end{array}$ & 6 \\
C & $\begin{array}{l}\text { Não prescrever contraceptivo e orientar a adolescente para que converse } \\
\text { primeiro com os pais }\end{array}$ & 6 \\
A & O profissional deve indicar preservativo e não envolver os pais & 4 \\
\hline
\end{tabular}

Também na situação "Atendendo adolescentes", as respostas dos estudantes indicam tendência a resguardar a vida por meio da compreensão e do acolhimento da paciente, considerando a complexidade da situação. O cuidado à saúde de adolescentes, que têm os pais ou outros adultos como responsáveis, é tema conflituoso do ponto de vista bioético, visto que traz desafios na 
questão do sigilo, da confidencialidade e dos vínculos. O profissional deve procurar compreender o contexto social e familiar dos adolescentes para encontrar soluções para os dilemas ${ }^{25,26}$.

Foi possível perceber conexões entre as escoIhas de cursos de ações e as respostas às perguntas "O que é ética para você?" e "Como você vê a importância da ética na profissão de odontologia?". Os estudantes se mostraram especialmente preocupados com o respeito aos direitos do paciente:

"Cada ação do dentista deve ser baseada em princípios éticos que respeitem os direitos humanos e, por conseguinte, os pacientes. Não seria correto, por exemplo, um profissional de odontologia deixar de informar seu paciente sobre riscos de um tratamento, ou então deixar de priorizar a sua saúde (...) Deve haver muita ética envolvida para que um serviço justo e eficiente seja oferecido à sociedade" (E5).

"Ética na odontologia é de muita relevância pois orienta o profissional (...) a fazer o melhor/certo para cada paciente e em cada caso, distintos um do outro, (...) deixando sempre em primeiro lugar a saúde" (E58).

A preferência dos estudantes por cursos de ação intermediários, na tentativa de respeitar os valores em conflito sem priorizar uma das pessoas envolvidas, pode estar relacionada à compreensão do profissional de saúde como responsável por maximizar a qualidade de vida:

"Ética profissional envolve solidariedade e comprometimento com o outro, além de respeito" (E11).

"[Ética profissional é] cumprir os valores e atividades da profissão. É proceder bem e não prejudicar o próximo. É agir com responsabilidade, honestidade e competência" (E49).

"A ética é importante na odontologia porque nossa função é cuidar da saúde de outras pessoas $e$, por ser uma grande responsabilidade, nossos valores devem nos guiar a fazer o melhor possível ao próximo" (E18).

"Vejo [a ética] como um pilar sustentador para ser um grande profissional. Pois a área de odontologia lida diretamente com pessoas de realidades diversas, logo o senso ético do(a) dentista sabe que o tratamento deve ser o mesmo, independente das diferenças. Outra forma como a ética se aplica é no modo de tratamento, ao se comunicar etc." (E28).

Ao ingressar no curso de odontologia e antes do contato com o estudo da bioética, os estudantes trazem concepções de ética próximas ao conceito de moral, restritas à ideia de que haveria uma solução "certa ou errada" para os conflitos. Alguns discursos analisados, porém, expressam uma amplitude maior de análise, que alia compreensões interculturais com a percepção bioética como orientadoras da tomada de decisões:

"[Ética é um] conjunto de valores e ideais que norteiam o comportamento dos indivíduos em todos os âmbitos em que estão inseridos, sendo a responsável pelas decisões mais simples até as mais complexas. (...) É preciso medir as consequências e repercussões que suas ações terão na vida dos outros e procurar pela melhor alternativa possível" (E27).

"Acredito que na área da odontologia a ética é importante tanto no relacionamento com o paciente quanto na decisão de que tratamento realizar (...). Na questão da decisão sobre que tratamento realizar, a ética é fundamental para realmente analisar caso por caso e não simplesmente realizar o mais prático para o profissional" (E46).

"A partir do pensamento ético dos indivíduos, alguns valores como respeito e responsabilidade perpetuam-se no ambiente, colaborando para um espaço mais acessível e agradável a todos que nele convivem. A ética também é importante no momento de tomar decisões corretas" (E5).

"Acredito que a ética é um conceito em constante transformação e construção, visando se adaptar à realidade e ao contexto do momento (...), pois trata do aperfeiçoamento da convivência na sociedade, a qual se modifica frequentemente" (E48).

Os estudantes recorrem a princípios bioéticos para sustentar a tomada de decisão, como também percebido em estudo de Brondani e Rossoff ${ }^{27}$.

Quanto a métodos de ensino, há formas de abordar conflitos éticos que facilitam a compreensão dos estudantes. É possível, por exemplo, encenar situações que exijam mediação. Métodos como esse transformam o debate bioético, tradicionalmente teórico, em vivência ${ }^{28}$. A experiência 
de processos de formação inseridos na realidade produz conhecimento e assegura a construção contínua e renovadora do aprendizado. Essa percepção é evidenciada no discurso dos estudantes.

É importante que ao longo da formação o estudante aperfeiçoe a escuta qualificada e a comunicação, verbal e não verbal, desenvolvendo uma "dimensão perceptiva" que fortaleça o vínculo profissional-paciente e a construção de projetos terapêuticos ${ }^{29}$. Além disso, é necessário estimular o diálogo ético interdisciplinar, uma vez que a união de profissionais reduz a dubiedade na tomada de decisão e eleva a coparticipação. A deliberação coletiva ampara uma reflexão crítica sobre os acontecimentos, o debate e a busca de soluções sensatas diante de conflitos éticos ${ }^{30}$.

\section{Considerações finais}

O estudo analisou conceitos éticos que os estudantes trazem consigo antes de ingressar no curso de odontologia, comparando-os com a tomada de decisão desses mesmos estudantes em situações fictícias que envolvem conflitos bioéticos. Nas respostas aos dilemas apresentados, os participantes revelaram tendência de tentar equilibrar os princípios em conflito, buscando soluções intermediárias. Mesmo sem experiência clínica, os estudantes se mostraram capazes de indicar cursos de ação que contemplam não somente o atendimento e tratamento em saúde, mas também o acolhimento, o cuidado e o respeito à vida.

Conclui-se que debater temas e conceitos da bioética na graduação pode ampliar o entendimento dos futuros profissionais sobre como as práticas de cuidado devem respeitar os direitos do paciente, apontando também para a importância de que os benefícios da ciência estejam em equilíbrio com as exigências da produção da vida. O estudo da bioética é potente para desenvolver a consciência de que indivíduos são seres complexos, que devem ser cuidados de forma integral, com respeito a suas crenças e cultura.

Os cursos de ação não podem se limitar à aplicação de técnicas e protocolos, numa perspectiva que reduz as diversas situações do universo da saúde aos limites morais dos códigos deontológicos. Nesse sentido, o discurso dos participantes do presente estudo confirma a importância da bioética como alicerce para tomadas de decisão que primam pelos princípios de autonomia, justiça, beneficência e não maleficência.

\section{Referências}

1. Gracia D. Pensar a bioética: metas e desafios. São Paulo: Loyola; 2010.

2. Junges JR. Metodologia da análise ética de casos clínicos. Bioética [Internet]. 2003 [acesso 10 mar 2020];11(1):33-42. Disponível: https://bit.ly/3t4XGtj

3. Monique Pyrrho M, Prado MM, Cordón J, Garrafa V. Análise bioética do Código de Ética Odontológica brasileiro. Ciênc Saúde Coletiva [Internet]. 2009 [acesso 10 mar 2020];14(5):1911-8. DOI: 10.1590/ S1413-81232009000500033

4. Santos LV, Curi JP, Coltri MV, Faggioni MS, Melani RFH, Arcieri RM, Beaini TL. A evolução do Código de Ética Odontológico brasileiro. Rev Bras Odontol Leg RBOL [Internet]. 2020 [acesso 15 dez 2020];7(2):81-99. DOI: $10.21117 /$ rbol-v7n22020-330

5. Armendane GD. Por um cuidado respeitoso. Rev. bioét. (Impr.). [Internet]. 2018 [acesso 10 mar 2020];26(3):343-9. DOI: 10.1590/1983-80422018263253

6. Zoboli E. A aplicação da deliberação moral na pesquisa empírica em bioética. Rev Iberoam Bioét [Internet]. 2016 [acesso 10 mar 2020];(2):1-19. DOI: 10.14422/rib.i02.y2016.006

7. Warmling CM, Pires FS, Baldisserotto J, Levesque M. Ensino da bioética: avaliação de um objeto virtual de aprendizagem. Rev. bioét. (Impr.). [Internet]. 2016 [acesso 10 mar 2020];24(3):503-14. DOI: 10.1590/1983-80422016243150

8. Warmling CM, Fajardo AP, Meyer DE, Bedos C. Práticas sociais de medicalização e humanização no cuidado de mulheres na gestação. Cad Saúde Pública [Internet]. 2018 [acesso 16 dez 2020]; 34(4). DOI: 10.1590/0102-311X00009917 
9. Yin RK. Estudo de caso, planejamento e métodos. $2^{\mathrm{a}}$ ed. São Paulo: Bookman; 2001.

10. Moraes R, Galiazzi MC. Análise textual discursiva: processo reconstrutivo de múltiplas faces. Ciênc Educ [Internet]. 2006 [acesso $1^{\circ}$ dez 2020];12(1):117-28. DOI: 10.1590/S1516-73132006000100009

11. Gonçalves PE, Garbin CAS, Garbin AJI, Saliba NA. Análise qualitativa do conteúdo ministrado na disciplina de bioética nas faculdades de odontologia brasileiras. Acta Bioeth [Internet]. 2010 [acesso $10 \mathrm{mar}$ 2020];16(1):70-6. DOI: 10.4067/S1726-569X2010000100010

12. Finkler M, Negreiro DP. Formação $x$ educação, deontologia $x$ ética: repensando conceitos, reposicionando docentes. Rev Abeno [Internet]. 2018 [acesso 10 mar 2020];18(2):37-44. DOI: 10.30979/rev.abeno.v18i2.561

13. Lima ENA, Souza ECF. Percepção sobre ética e humanização na formação odontológica. Rev Gaúcha Odontol [Internet]. 2010 [acesso 10 mar 2020];58(2):231-8. Disponível: https://bit.ly/3gOb5n3

14. Veiga-Neto A. Didática e as experiências de sala de aula: uma visão pós-estruturalista. Educação e Realidade [Internet]. 1996 [acesso 10 mar 2020];21(2):161-75. Disponível: https://bit.ly/3vsoFk3

15. Amorim AG, Souza ECF. Problemas éticos vivenciados por dentistas: dialogando com a bioética para ampliar o olhar sobre o cotidiano da prática profissional. Ciênc Saúde Coletiva [Internet]. 2010 [acesso 10 mar 2020];15(3):869-78. DOI: 10.1590/S1413-81232010000300030

16. Patrick AC. A review of teaching ethics in the dental curriculum: challenges and future developments. Eur J Dent Educ [Internet]. 2017 [acesso 10 mar 2020];21(4):114-8. DOI: 10.1111/eje.12230

17. Freitas CHSM. Dilemas no exercício profissional da odontologia: a autonomia em questão. Interface Comun Saúde Educ [Internet]. 2007 [acesso 10 mar 2020];11(21):25-38. DOI: 10.1590/S1414-32832007000100004

18. Finkler M, Caetano JC, Ramos FRS. Ética e valores na formação profissional em saúde: um estudo de caso. Ciênc Saúde Coletiva [Internet]. 2013 [acesso 10 mar 2020];18(10):3033-42. DOI: 10.1590/ S1413-81232013001000028

19. Marin F, Rebello M, Mello ALSF, Finkler M. Ética e bioética como temas de pesquisa em odontologia: uma análise bibliométrica dos trabalhos apresentados nas reuniões da SBPQO. Rev Abeno [Internet]. 2016 [acesso 10 mar 2020];16(4):51-60. DOI: 10.30979/rev.abeno.v16i4.339

20. Holden ACL. Reflections on the encouragement of altruism in dental education. Eur J Dent Educ [Internet]. 2018 [acesso 10 mar 2020];22(1):198-202. DOI: 10.1111/eje.12247

21. Naidoo S. Ethical considerations in community oral health. J Dent Educ [Internet]. 2015 [acesso 10 mar 2020];79(5 Suppl):38-44. Disponível: https://bit.ly/3nrd1mC

22. Junges JR, Zoboli ELCP. Bioética e saúde coletiva: convergências epistemológicas. Ciênc Saúde Coletiva [Internet]. 2012 [acesso 10 mar 2020];17(4):1049-60. DOI: 10.1590/S1413-81232012000400026

23. Ardenghi DM. Dentists' ethical practical knowledge: a critical issue for dental education. Eur J Dent Educ [Internet]. 2009 [acesso 10 mar 2020];13(2):69-72. DOI: 10.1111/j.1600-0579.2009.00575.x

24. Matos MS, Tenório R. Percepção de alunos, professores e usuários acerca da dimensão ética na formação de graduandos de odontologia. Ciênc Saúde Coletiva [Internet]. 2010 [acesso 10 mar 2020];15(2 Supl):3255-64. DOI: 10.1590/S1413-81232010000800031

25. Taquette SR, Vilhena MM, Silva MM, Vale MP. Conflitos éticos no atendimento à saúde de adolescentes. Cad Saúde Pública [Internet]. 2005 [acesso 10 mar 2020];21(6):1717-25. DOI: 10.1590/S0102311X2005000600019

26. Hertrampf K, Groß D, Karsten G, Wenz HJ. The influence of clinical experience on dental students' ethical awareness. Eur J Dent Educ [Internet]. 2018 [acesso 10 mar 2020];23(2):101-9. DOI: 10.1111/eje.12408

27. Brondani MA, Rossoff LP. The "hot seat" experience: a multifaceted approach to the teaching of ethics in a dental curriculum. J Dent Educ [Internet]. 2010 [acesso 10 mar 2020];74(11):1220-9. Disponível: https:// bit.ly/3xuuSOn

28. Lantz MS, Bebeau MJ, Zarkowski P. The status of ethics teaching and learning in U.S. dental schools. J Dent Educ [Internet]. 2011 [acesso 10 mar 2020];75(10):1295-309. Disponível: https://bit.ly/3xDD2E2

29. Lucander H. An instrument to assess dental students' competence in shared decision making: a pilot study. J Dent Educ [Internet]. 2017 [acesso 10 mar 2020];81(12):1463-71. DOI: 10.21815/jde.017.108

30. Dalla Nora CR, Zoboli ELCP, Vieira MM. Deliberação ética em saúde: revisão integrativa da literatura. Rev. bioét. (Impr.). [Internet]. 2015 [acesso 10 mar 2020];23(1):114-23. DOI: 10.1590/1983-80422015231052 
Michelli Justen - Graduanda - michellijusten@gmail.com (D) 0000-0001-8508-9240

Fabiana Schneider Pires - Doutora - fabianaspires@gmail.com

(iD) 0000-0001-6545-524X

Cristine Maria Warmling - Doutora - crismwarm@gmail.com.br (D) 0000-0003-2259-4199

\section{Correspondência}

Cristine Maria Warmling - Rua Dona Leonor, 194/1407 CEP 90420-180. Porto Alegre/RS, Brasil.

Participação das autoras

Michelli Justen planejou o desenho do estudo, coletou e analisou os dados e estruturou o manuscrito. Fabiana Schneider Pires e Cristine Maria Warmling orientaram a pesquisa e colaboraram com a fundamentação teórica. Todas as autoras contribuíram com a redação do artigo. 